\title{
Utilization of Zinc-Ferrite/ Water Hybrid Nanofluids for enhancing thermal performance of a Flat Plate Solar Collector -An Analytical Study
}

Prakasam Michael Joseph stalin ( $\sim$ pmjstalin@gmail.com )

ASCET: Audisankara College of Engineering and Technology

Thottipalayam Vellingri Arjunan

Guru Ghasidas Vishwavidyalaya: Guru Ghasidas University

Mohammed Abdulrahman Almeshaal

Imam Muhammad bin Saud Islamic University: Imam Muhammad Ibn Saud Islamic University

Palaniappan Murugesan

Imam Muhammad Ibn Saud Islamic University

Balaramachandran Prabu

Christian College of Engineering

Pasupathi Manoj Kumar

KPR Institute of Engineering and Technology

\section{Research Article}

Keywords: Solar collector, Hybrid Nanofluid, Zinc-ferrite/Water, Thermal performance, Exergy

Posted Date: November 15th, 2021

DOI: https://doi.org/10.21203/rs.3.rs-976278/v1

License: (9) (i) This work is licensed under a Creative Commons Attribution 4.0 International License.

Read Full License 


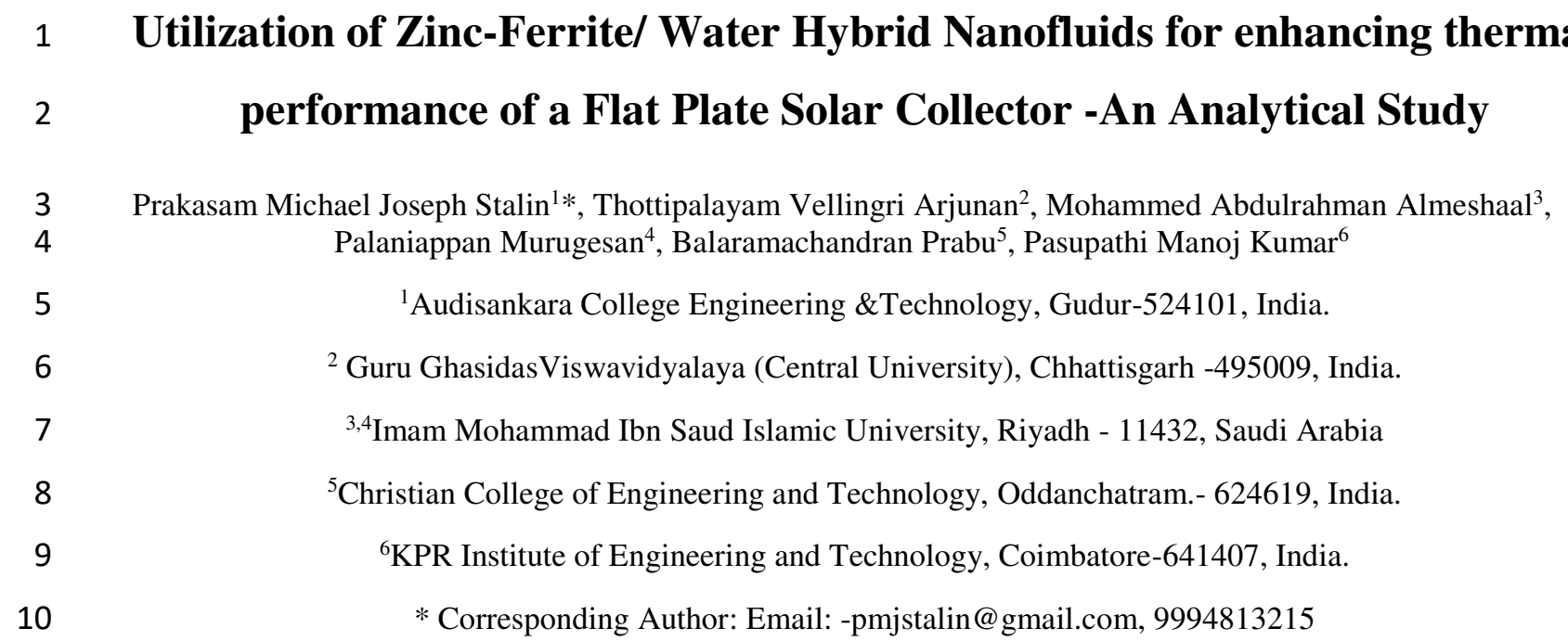

11 Abstract:

Thermodynamic performance analysis is carried out on a flat plate solar thermal collector

utilizing single and hybrid nanofluids. As heat transfer fluids, $\mathrm{Fe}_{2} \mathrm{O}_{4} /$ water, $\mathrm{Zn}-\mathrm{Fe}_{2} \mathrm{O}_{4} /$ water hybrid

nanofluids, and water are used, and its performance are compared based on the energy and exergy transfer rate. The thermo-physical properties are evaluated by regression polynomial model for all the working fluids. Developed codes in MATLAB solve the collector's thermal model iteratively, energy and exergetic performance are evaluated. The system was then subjected to parametric investigation and optimization for variations in fluid flow rate, temperatures, and concentrations of nanoparticles. The findings show that utilizing $\mathrm{Zn}-\mathrm{Fe}_{2} \mathrm{O}_{4} /$ water hybrid nanofluids with a particle concentration of 0.5 percent enhanced the solar collector's thermal performance by $6.6 \%$ while using $\mathrm{Fe}_{2} \mathrm{O}_{4}$ /water nanofluids raised the collector's thermal performance by $7.83 \%$ when compared to water as the working fluid. While hybrid nanofluids give a better thermal alternative than water and single nanofluids, they have also produced a 5.36\% increase in exergetic efficiency and an enhancement of 8.24 percent when used with $\mathrm{Fe}_{2} \mathrm{O}_{4}$ /water nanofluids.

Keywords: Solar collector, Hybrid Nanofluid, Zinc-ferrite/Water, Thermal performance, Exergy.

\section{Introduction}

Solar energy is a free, widely available, and non-polluting fastest developing renewable energy source that may be utilized for power generation as well as heating applications like space heating, drying, and water heating. Domestic water heating consumes around $6 \%$ of total global energy consumption. Solar energy converting devices are capable of reliably converting the 
31 absorbed solar radiation into heat energy for the working fluids. Flat plate collectors are economically feasible and extensively used solar thermal collectors. FPCs, on the other hand, have several design flaws, including low efficiencies, significant heat losses, and insufficient solar absorption efficiency. Enhancing the engineering and scientific restrictions of flat plate collectors may decrease the conventional energy generations and environmental issues associated with energy consumption.

"Nanofluid" has now become an eminent technique used enhancing the rate of energy transfer in the equipment for process heating applications. The experimental studies have been done to evaluate the thermo-physical properties of several nanofluids as a function of temperature (Esfe Mohammad Hemmat and Seyfolah Saedodin 2015; Abbasi et al.2016; Stalin et al.2017) because the engineering precision of energy converting devices is strongly reliant on the features of fluids used for heat transfer. Latest trends in manufacturing processes have enabled the production of nanoparticles. The magnetic, thermal, optical, mechanical, and electrical characteristics of nanoparticles $\leq 100 \mathrm{~nm}$ is superior. This gain is because of raise in surface area to volume ratio at grain boundaries, generated by a larger atom group (Chakraborty and Panigrahi 2020). The nanofluids created minimize the agglomeration and improve heat conductivity by dispersing nanoparticles in a base fluid (Hamilton and Crosser 1962).Surfactants added to nanofluids can dramatically decrease agglomeration. The study has been created the distributing micro-sized solid particles in working fluids to improve heat conductivity (Choi and Eastman 1995). Its use in practical applications has been restricted by the coagulation problem related to micro-sized elements.

The thermal conductivity enhances with the rise in temperature of the nanofluid, according to a large amount of research work on modeling, characterization, synthesis, convective and phase change heat transfer during the previous decade (Das et al.2003). Nanofluids outperform conventional fluids in terms of thermo-physical properties, heat transfer coefficient, thermal efficiency, and optical absorptivity, according to several studies (Bobbo et al.2012; Fedele et al.2012; Murshed et al.2005; Pak and Cho 1998; Said et al.2014; Sajid et al.2014; Vajjha et al.2009). Tyagi et al. [15] assessed the thermal performance of $\mathrm{Al}_{2} \mathrm{O}_{3}$ /water-based nanofluids flowing through the tubes of direct absorption solar collector (DAC) known as a typical solar flatplate collector, finding that the DAC is up to $10 \%$ more efficient. The author studied the influence 
of $\mathrm{CuO} /$ water-based nanofluid on heat transfer characteristics of the FPSC in laminar flow conditions (Khin et al. 2016). Their research was based on calculating the thermal efficiency of nanoparticles as a role of their size and volume concentration size. It is revealed that as the concentration rises to $2.0 \%$, the energy efficiency improves, but that the volume of the nanoparticles has little consequence on the performance. They found that at an optimum flow rate of $1.2 \mathrm{~kg} / \mathrm{min}$, two wt $\% \mathrm{CuO} /$ water nanofluid improves FPSC efficiency by up to $5 \%$. It has been reported that the 5\% improvement in solar thermal collector performance with nanofluids as an absorbing medium (Otanicar et al.2010).

According to experimental and theoretical findings, nanofluids are very gifted and set to be substituted by usual fluids to improve solar collectors' efficiency. The improved thermal performance achieved by utilizing nano fluid has aided research in these sectors to find another way to reduce costs while increasing thermal performance. Hybrid nanofluids are a type of advanced fluid that has been produced to have a certain thermos physical characteristic. Because of the enhancement in thermal characteristics, the mixture of several nano powders with numerous base fluids, known as "hybrid nano fluid" (HNF), has been demonstrated apparently in many uses (Minea 2017). The author studied the numerous real-world applications that need dynamic compatibility between many factors, bringing hybrid nano fluid into the picture (Sarkar et al. 2015). This research aims to investigate whether a hybrid nano fluid could provide better thermal conductivity than separate nanofluids produced from $\mathrm{Al}_{2} \mathrm{O}_{3}$ and $\mathrm{CuO}$ powders using a hydrogen reduction method in a 90:10 ratio. According to measurements, the enhancement in thermal conductivity is comparatively lower with the rise in viscosity values (Suresh et al. 2011).

The study was focused the forced convective heat transfer for water, ethylene glycol, CNTs and $\mathrm{Al}_{2} \mathrm{O}_{3}$ based hybrid nanofluids by adopting the two-phase mixture model. The results reveal that utilizing ethylene glycol instead of water as a base fluid increases energy transmission (Labib et al.2013). This research work quantitatively investigated the $\mathrm{Al}_{2} \mathrm{O}_{3}$ /water nanofluid at turbulent flow operating conditions with constant heat flux on the wall (Bianco et al.2011). They evaluated the findings in different concentrations using multi-phase models. This paper showed numerical simulations to analyze an $\mathrm{Al}_{2} \mathrm{O}_{3}$ /water nanofluid using a novel method called the two-phase Eulerian model. It results that there is a greater agreement with experimental results when compared to a single-phase model (R. Lotfi et al. 2010). These studies investigated the laminar 
convection of nanofluids using an Eulerian-Lagrangian approach (He et al. 2009; Bianco et al.2009). Their observations were compared to the available experimental data. The zinc/ferrite nanoparticles have improved value of stability which is advantageous for using longer periods. Temperature-sensitive ferro fluids are also used in the hybrid nanofluids under research, resulting in enhanced value of thermo-physical properties (Sundar et al.2017). Further, several reports have been published that adding $\mathrm{ZnO}$ and $\mathrm{Fe}_{2} \mathrm{O}_{4}$ particles on nanofluid shows a significant improvement in the value of thermal conductivity. According to the authors' knowledge, no research on $\mathrm{Zn}$ $\mathrm{Fe}_{2} \mathrm{O}_{4} /$ water hybrid nanofluids for evaluating solar collectors has been reported.

This research presents first and second law-based analysis of an FPSC using single and Zn$\mathrm{Fe}_{2} \mathrm{O}_{4}$ /water hybrid nanofluids. The user-developed code in MATLAB was used to analyze and enhance a proposed thermal model. The thermal model is developed based on the energy balance equations, updated to account for the effects of new single and hybrid nanofluids (Gupta et al.2020). Moreover, the thermal performance, exergy analysis, entropy generation, exergy destruction, and Bejan number of the nanofluids in the FPSC are evaluated with a functional evaluation of different operating temperatures, nanoparticle concentration, and flow rates. Finally, these parameters are subjected to impact analysis and optimization to get the collector's highest possible performance enhancement yield when used with each nanofluid.

\section{Theoretical analysis}

The FPSC is a solar collector consist an absorber plate and it was covered by transparent glass cover at top and thermal insulation at bottom for minimizing the heat losses. The riser tubes integrated with the absorber plate to collect and transfer the heat to the working fluid. The solar radiation penetrates over the transparent cover made up of glass and strike over the surface of the absorber plate, which has an extremely higher rate of absorptivity. The absorber plate is designed to collect the maximum amount of solar energy possible. By minimizing the stationary air formulation between the glass cover and the heated absorber plate, decreases absorber plate heat loss caused by the wind. It also aids in decreasing the collector's radiative heat losses by making wave length of in the range of 3-100 $\mu$ released by the heated plate. The nano fluid running within the risers absorbs a large amount of heat energy received by the hot absorber plate. Figure 1 represents astructure of the FPSC. The size and characteristics of the FPSC are listed in Table 2. 
This section includes the equations that were utilized to describe the flat plate collector

121 (FPC). The system, nanofluids and fluid flow area are all detailed and modelled in the following 122 sections. The analytical work is carried out with an assumption that the system properties are not 123 varies with time and the heat flows are homogeneous. In theoretical analysis, all of the risers have 124 equal flow rate, whereas the central axis connecting the risers and absorber plate are both in the 125 same path (refer Fig. 1)

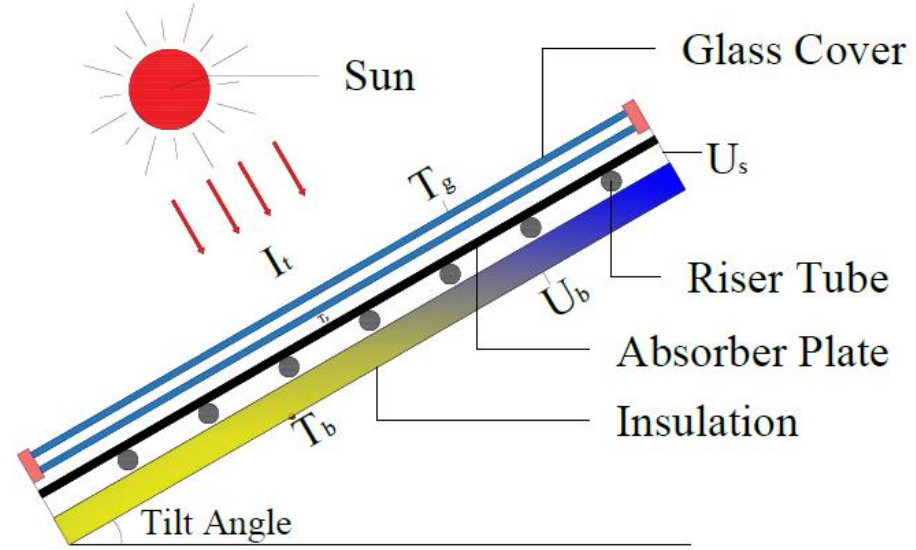

Fig.1.Schematic layout of flat plate solar collector

128 Table 1

129 Design parameters for the solar collector under investigations

\begin{tabular}{|c|l|c|}
\hline Sl.No & \multicolumn{1}{|c|}{ Parts } & Specifications \\
\hline 1 & Collector area $\left(\mathrm{A}_{\mathrm{c}}\right)$ & $2 \mathrm{~m}^{2}$ \\
\hline 2 & Riser tubes length $(\mathrm{L})$ & $2000 \mathrm{~mm}$ \\
\hline 3 & Collector tilt angle $(\beta)$ & $15^{\circ}$ \\
\hline 4 & Back insulation thickness $\left(\mathrm{t}_{\mathrm{b}}\right)$ & $25 \mathrm{~mm}$ \\
\hline 5 & Side insulation thickness $\left(\mathrm{t}_{\mathrm{s}}\right)$ & $0.454 \mathrm{~mm}$ \\
\hline 6 & Absorber plate thickness $\left(\mathrm{t}_{\mathrm{p}}\right)$ & $384 \mathrm{~W} / \mathrm{m} \mathrm{K}$ \\
\hline 7 & Absorber plate thermal conductivity $\left(\mathrm{k}_{\mathrm{p}}\right)$ & \\
\hline
\end{tabular}




\begin{tabular}{|c|l|c|}
\hline 8 & Absorbance $(\alpha)$ & 0.962 \\
\hline 9 & Transmittance $(\tau)$ & 0.87 \\
\hline 10 & Number of glass cover $(\mathrm{N})$ & 1 \\
\hline 11 & glass covers emissivity of $\left(\varepsilon_{\mathrm{c}}\right)$ & 0.88 \\
\hline 12 & Ambient temperature & $25^{\circ} \mathrm{C}$ \\
\hline 13 & Emissivity of absorber plate $\left(\varepsilon_{\mathrm{p}}\right)$ & 0.92 \\
\hline 14 & Distance between risers $(9 \mathrm{Nos})(\mathrm{W})$ & $95 \mathrm{~mm}$ \\
\hline 15 & Riser pipeinner diameter $\left(\mathrm{D}_{\mathrm{i}}\right)$ & $9.5 \mathrm{~mm}$ \\
\hline 16 & Riser pipeouter diameter $\left(\mathrm{D}_{\mathrm{o}}\right)$ & $10 \mathrm{~mm}$ \\
\hline 17 & Diameterof the header pipe $(\mathrm{D})$ & $25 \mathrm{~mm}$ \\
\hline 18 & Speed of the wind $\left(\mathrm{V}_{\mathrm{w}}\right)$ & $1 \mathrm{~m} / \mathrm{s}$ \\
\hline 19 & Incident solar radiation $\left(\mathrm{I}_{\mathrm{t}}\right)$ & $800 \mathrm{Wm}$ \\
\hline
\end{tabular}

\subsection{Energy Analysis.}

The useful gain that transfer to the working fluid of flat plate collector is evaluated by using the Eq. (1) ( Ozil and Yaşar 1987):

$$
Q_{u}=I_{t} \cdot A_{c} \cdot(\tau \alpha)-U_{L}
$$

In the equation $1 \mathrm{I}_{t}$ represents solar energy input to the FPSC per area, $\mathrm{A}_{\mathrm{c}}$ indicates area of absorber plate that receives the input energy, $(\tau \alpha)$ is the combined influence of transmittance of glass cover 137 and the absorptance of absorber plate surface and $U_{L}$ shows the overall loss coefficient of the 138 collector.

A flat plate collector's efficiency $(\eta)$ is defined as the proportion of usable energy $\left(\mathrm{Q}_{\mathrm{u}}\right)$ to 140 total incident solar energy on the solar collector area:

$141 \quad$ Efficiency $=\frac{Q_{u}}{A_{c} I_{t}} \times 100$ 
142 The energy loss from the collector is shown in Q1. Eq. (3) (Duffie and Beckman 2013), it includes 143 all the losses happens by the three modes of heat transfer.

$$
Q_{l}=U_{l} \cdot A_{C}\left(T_{p}-T_{o}\right)
$$

145

146

147

148
$\mathrm{T}_{\mathrm{p}}$ and $_{\mathrm{o}}$ indicate absorber plate and the surrounding environment temperature, respectively. Further, $\mathrm{Ut}$, $\mathrm{Us}$ and $\mathrm{U}_{\mathrm{b}}$ represents top loss, bottom loss and side loss from the systemThe summation of all three losses yields the total heat loss from the system.

$$
U_{l}=U_{t}+U_{b c}+U_{s}
$$

Eq.(5) gives the top loss coefficient (Ut);

$$
U_{t}=\frac{1}{\frac{N}{\frac{C}{T_{p}}\left[\frac{T_{p}-T_{o}}{N-f}\right] 0.31+\frac{1}{h_{c}, \infty}}}+\frac{\sigma\left(T_{p}^{2}-T_{o}^{2}\right)\left(T_{p}-T_{o}\right)}{\frac{1}{\varepsilon_{p l}+0.0425 N\left(1-\varepsilon_{p l}\right)}+\frac{2 N+f-1}{\varepsilon_{g}}-N}
$$

where

$\varepsilon_{\mathrm{pl}} \quad=$ Absorber plate Emissivity

$\varepsilon_{\mathrm{g}} \quad=$ Glass cover emissivity

$\sigma \quad=$ Stefan-Boltzmann constant

$\mathrm{h}_{\mathrm{c}}=$ Wind heat transfer coefficient

$\mathrm{N} \quad$ = quantity of glass cover

The convective heat loss coefficient between FPSC and ambient air are evaluated by the Eqs. (6)-(8) (Ozil and Yaşar 1987). Further, the constants $\mathrm{f}$ and $\mathrm{C}$ is given by

$$
h_{c}=\frac{8.6 V_{W}^{0.6}}{L^{0.4}}
$$

$$
C=\left(1-0.00883 \beta+0.0001298 \beta^{2}\right) 365.9
$$


162 Where, $\mathrm{V}_{\mathrm{w}}$ and $\mathrm{L}$ are the wind speed and collector length, respectively. The heat loss happens at 163 the bottom of the collector is directly proportional to the thermal conductivity $\left(\mathrm{k}_{\mathrm{b}}\right)$ of the insulation, 164 bottom heat loss coefficient $\left(\mathrm{h}_{\mathrm{b}}\right)$ and indirectly proportional to the thickness of insulation $\left(\mathrm{t}_{\mathrm{b}}\right)$.

165 It is evaluated using the relation as follows (Mahian et al.2014):

166

$$
U_{b c}=\frac{1}{\frac{t_{b}}{k_{b}}+\frac{1}{h_{b}}}
$$

167 The energy loss from the edges of FPSC is given by Eq. (10).

168

$$
U_{s}=\frac{1}{\frac{t_{s}}{k_{s}}+\frac{1}{h_{s}}} \frac{A_{s}}{A_{c}}
$$

169 Where, $\mathrm{t}_{\mathrm{b}}$ denotes the thickness of the insulation in the bottom region, $\mathrm{t}_{\mathrm{s}}$ denotes the thickness of 170 the insulation edge, and $\mathrm{k}_{\mathrm{b}}$ denotes the thermal conductivity of the insulation in the bottom surface.

$171 \mathrm{k}_{\mathrm{s}}$ is the insulation's thermal conductivity at the margins and $\mathrm{A}_{\mathrm{s}}$ is the area of the edges' surface.

$172 U_{t}$ and $U_{1}$ are depending on the temperature of the absorber plate $T_{p}$, as shown in Eq.(11). As a 173 result, Eq.(11) (Kalogirou 2009) is provided as an equation to determine the plate temperature:

$$
T_{p}=T_{i n}+\frac{Q_{u}}{A_{c} F_{R} U_{L}}\left(1-F_{R}\right)
$$

$$
F_{R}=\frac{\dot{m} C_{p}}{A_{c} U_{L}}\left[1-\exp \left(-\frac{U_{L} F A_{c}}{\dot{m} C_{p}}\right)\right]
$$

178 In the Eq.(13) (Kalogirou 2009), F' represents the collector efficiency factor. The following 179 formula can be used to compute the factor:

$$
F^{\prime}=\frac{\frac{1}{U_{L}}}{W\left[\frac{1}{U_{L}(W-D) F}+\frac{1}{\pi D_{i} h_{f}}\right]}
$$


181 In the above equation $\mathrm{W}$ indicates the tube spacing, $\mathrm{D}$ represents riser tube diameter at outer side, $182 \mathrm{~h}_{\mathrm{f}}$ indicates coefficient of heat transfer and $\mathrm{D}_{\mathrm{i}}$ denote, riser tube diameter at inner side respectively. 183 The fin efficiency of the collector is evaluated using the relation as follows (Kalogirou 2009):

$$
F=\frac{\tanh [(W-D) m / 2]}{(W-D) m / 2}
$$

185 Where, $\mathrm{m}=\sqrt{\frac{U_{L}}{k_{p} t_{p}}}$ in which thermal conductivity and absorber plate thickness are represented by $186 \mathrm{kp}$ and $\mathrm{tp}$, correspondingly.

187 For laminar flow conditions, the internal heat transfer coefficient $\left(\mathrm{h}_{\mathrm{f}}\right)$ is calculated using 188 Eq.(15).

$$
h_{f i}=\frac{48 k_{n f}}{11 D_{i}}
$$
191 way.

$$
\operatorname{Re}=\frac{4 m_{r}}{\pi D_{i} \mu_{n f}}
$$

193

$194 \quad \operatorname{Pr}=\frac{\mu_{n f} C_{p, n f}}{k_{n f}}$ to determine the temperature of working fluids at their outlet.

197

$$
T_{\text {out }}=T_{\text {in }}+\frac{Q_{u}}{\dot{m} C_{p}}
$$

\subsection{Exergy Analysis}

Exergy refers to the transformation of available energy into productive work or energy and so specifies the compactness of the thermal system. Exergy efficiency is the maximum amount of useful work that a system may generate, and it is defined as follows: 


$$
\eta_{e x}=\frac{E_{u}}{E_{\text {sun }}}
$$

204 (Okonkwo et al.2019; Ratlamwala et.al.2019) can be used to determine solar exergy:

205

$$
\dot{E}_{\text {sun }}=A_{c} I_{t}\left(1-\frac{4}{3}\left(\frac{T_{o}}{T_{\text {sun }}}\right)+\frac{1}{3}\left(\frac{T_{o}}{T_{\text {sun }}}\right)^{4}\right)
$$

206

207

208

$$
\dot{S}_{\text {gen }}=\frac{\dot{w}_{\text {lost }}}{T_{o}}=\frac{\dot{E}_{d}+\dot{E}_{\text {loss }}}{T_{o}}
$$

214 The exergy loss to the environment is calculated as follows (Mahian et al.2014).

215

$$
E_{\text {loss }}=U_{l} A_{c}\left(T_{P}-T_{o}\right)\left(1-\frac{T_{o}}{T_{P}}\right)
$$

$$
\dot{E}_{d}=\dot{E}_{d, \Delta T_{s}}+\dot{E}_{d, \Delta P}+\dot{E}_{d, \Delta T_{f}}
$$

219 The exergy lost due to friction that happens between flowing fluid and collector wall surfaces, 220 enhances the drop in pressure and pumping power. It is calculated as follows: 


$$
\dot{E}_{d, \Delta P}=T_{o} \dot{m} \frac{\Delta P}{\rho} \frac{\ln \left(\frac{T_{\text {out }}}{T_{a}}\right)}{\left(T_{\text {out }}-T_{\text {in }}\right)}
$$

222 The loss of exergy occurs due to temperature difference between the Sun $\left(\mathrm{T}_{\mathrm{s}}\right)$ and the heated 223 absorber plate $\left(\mathrm{T}_{\mathrm{p}}\right)$ is $\dot{E}_{d, \Delta T_{S}}$ which is given by (Padilla et al.2014).

224

$$
\dot{E}_{d, \Delta T_{s}}=(\tau \alpha)_{e f f} I_{t} A_{c} T_{O}\left(\frac{1}{T_{p}}-\frac{1}{T_{\text {sun }}}\right)
$$

225

226

227

228

229

The Bejan number indicates the fraction of entropy generation that happens in the system only due to the heat transfer process. it is evaluated by

$$
B e=\frac{\left(\dot{S}_{g e n}\right)_{H}}{\dot{S}_{\text {gen }}}
$$

$$
\left(\dot{S}_{g e n}\right)_{H}
$$

\section{Determination of Hybrid Nanofluids Properties}

The correlations used to predict and characterize the thermal characteristics of $\mathrm{Zn}-\mathrm{Fe}_{2} \mathrm{O}_{4}$ Hybrid Nanofluids were obtained from the literature. The base fluid (bf) was used to define nanofluid, which consisted of a hybrid nanoparticle of $\mathrm{Zn}\left(\mathrm{n}_{\mathrm{p} 1}\right), \mathrm{Fe}_{2} \mathrm{O}_{4}$ nanoparticle $\left(\mathrm{n}_{\mathrm{p} 2}\right)$, and the hybrid nanofluids $\left(\mathrm{h}_{\mathrm{nf}}\right)$. The effect of using conventional single nanofluid at medium and high inlet temperatures was investigated for any nanoparticle with a particle volume fraction $(\varphi)$ of 0.5 
percent, while the calculated results for hybrid nanofluids occurred under different conditions for two distinct methods with a volume concentration $\left(\varphi_{\text {tot }}\right)$ of 0.5 percent. This overall particle volume fraction was split into 50:50 mixing fractions, resulting in a volume fraction of $0.25 \%$ for each nanoparticle. The total volume fraction is defined by the following equation, which may be used to characterize nanofluid in single or hybrid nanofluids.

The total volume fraction of hybrid nanofluids with conventional fluids obtained, as illustrated in Eq. (30) (Takabi et al.2014).

$$
\varphi_{\text {total }}=\varphi_{n p 1}+\varphi_{n p 2}
$$

The density of hybrid nanofluids is described in Eq. (31) and it has been discussed in several research papers (Bellos and Tzivanidis 2018; Rasih et al. 2019).

$$
\rho_{h n f}=\varphi_{n p 1} \cdot \rho_{n p 1}+\varphi_{n p 2} \cdot \rho_{n p 2}+\left(1-\varphi_{t o t a l}\right) \cdot \rho_{b f}
$$

To address single and hybrid Nanofluids, the specific heat capacity formula in Eq. (32) is utilized. Therefore, its capacity to cover a wide variety of particle volume concentrations as well as its application in various nanofluid types, this formula has been frequently utilized in the literature (Rasih et al. 2019).

$$
C_{p, n f}=\frac{\varphi_{n p 1} \cdot \rho_{n p 1} \cdot C_{p, n p 1}+\varphi_{n p 2} \cdot \rho_{n p 2} C_{p, n p 2}+\left(1-\phi_{t o t a l}\right) \cdot \rho_{b f} \cdot C_{p, b f}}{\rho_{h n f}}
$$

The thermal properties of nanofluids had been calculated using Maxwell correlation, as indicated in Eq. (33) (Rasih et al. 2019; Maxwell 1873), which was expanded to include hybrid and single nanofluids.

$$
k_{h n f}=\frac{\frac{\varphi_{n p 1} \cdot k_{n p 1}+\varphi_{n p 2} \cdot k_{n p 2}}{\varphi_{t o t a l}}+2 \cdot k_{b f}+2 \cdot\left(\varphi_{n p 1} \cdot k_{n p 1}+\varphi_{n p 2} \cdot k_{n p 2}\right)-2 \cdot \varphi_{t o t a l} \cdot k_{b f}}{\frac{\varphi_{n p 1} \cdot k_{n p 1}+\varphi_{n p 2} \cdot k_{n p 2}}{\varphi_{t o t a l}}+2 \cdot k_{b f}-2 \cdot\left(\varphi_{n p 1} \cdot k_{n p 1}+\varphi_{n p 2} \cdot k_{n p 2}\right)+\varphi_{t o t a l} \cdot k_{b f}}
$$

The dynamic viscosity of the nanofluid was estimated using the Brinkman model correlation, as stated in Eq. (34) (Brinkman 1952),

$$
\mu_{h n f}=\mu_{b f}\left(\frac{1}{\left(1-\varphi^{2.5}\right)}\right)
$$

The correlations that were utilized to describe the thermal characteristics of hybrid nanofluids were often taken from the earlier work, by (Mwesigye and Huan 2015) investigation pointed out. The 
264 following equations are applied for evaluating the properties of heating fluid is described below 265 (Mwesigye and Huan 2015).

266

267

268

269

270

271

272

273

274

275

276

277

278

279

280

281

282

283

284

285

286

287

288

$$
C_{p b f}=1.10787+1.70736 .10^{-3} T
$$

$$
\rho_{b f}=0.1291 \times 10^{-3}-1.52115 T+0.179133 .10^{-2} T^{2}-1.671545 T^{3}
$$

Eq. (38) for $343 \geq \mathrm{T} \geq 233.15 \mathrm{~K}$ and Eq. (39) for $673.15 \geq \mathrm{T} \geq 343 \mathrm{~K}$ illustrate characteristics of dynamic viscosity as function of inlet temperature of the fluid.

$\mu_{b f}=5.14 \times 10^{4}-\left(9.6165 .10^{2} T\right)+\left(7.502 \times T^{2}\right)-\left(0.31246 .10^{-3} \times T^{3}\right)+\left(0.7322 .10^{-6} \times T^{4}\right)-\left(0.01463 .10^{-9} \times T^{5}\right)$ $+\left(0.47562 .10^{-10} \times T^{6}\right)$

$\mu_{b f}=9.8856 .10-\left(7.309 \times 10^{-1} \times T\right)+\left(0.221917 \times 10^{-2} \times T^{2}\right)-\left(0.342377 \times 10^{-5} \times T^{3}\right)+\left(0.26683 \times 10^{-8} \times T^{4}\right)(39$

With respect to the findings, prior fundamental correlations described in this part is used to describe the thermal characteristics of these revised heat transfer fluids in terms of their capacity to forecast an acceptable outcome, as well as the lack of unique relationships to include oil in a high temperature range. In this work, the Nusselt number was utilized to address the hybrid nanofluids, whether it was for the conventional fluids, a single nanofluids, or to estimate the fluid's heat transfer coefficient. Because of its capability to cover diverse kinds of nanofluids, including alkali metals, Gupta's relation, as indicated by Eq.(40), was used to evaluate the Nusselt number for the hybrid nanofluids. The correlation was valid up to the volume concentration ratio of 0.10.5.\%. This equation is applied to the Nusselt number for the hybrid energy system as a consequence of this investigation (Gupta et al.2015).

$$
N u=0.2437 \operatorname{Re}^{0.4896} \operatorname{Pr}^{0.2847} \varphi^{0.1017}
$$

To include the resulting value of distinct monotypes, the Nusselt number for single nanofluid was calculated using Maiga's correlation. As a result, the validity of this equation has been demonstrated for a variety of nanoparticle kinds in a laminar environment. Equation 41 is utilized to calculate the Nusselt number is describing below (Maiga et al.2005).

$$
N u=0.086 \operatorname{Re}^{0.55} \operatorname{Pr}^{0.5}
$$


Table 2. Properties of the base fluid, $\mathrm{Zn}$ and $\mathrm{Fe}_{2} \mathrm{O}_{4}$ nanoparticles

\begin{tabular}{|c|c|c|c|c|}
\hline Sl.No & Properties & Water & ZnO & Fe2O4 \\
\hline 1 & Thermal conductivity (W/mK) & 0.52 & 29 & 80.4 \\
\hline 2 & Specific heat (J/kg K) & 4.187 & 514 & 670 \\
\hline 3 & Density (kg/m3) & 1000 & 5600 & 5180 \\
\hline
\end{tabular}

\section{Results and discussion}

The performance assessment of $\mathrm{Zn}-\mathrm{Fe}_{2} \mathrm{O}_{4}$ /water nanofluids was theoretically studied and the results obtained in this research work are presented in this section. Moreover, the second law analysis of the $\mathrm{Zn}-\mathrm{Fe}_{2} \mathrm{O}_{4}$ /water with various concentrations with respect to different mass flow rates has been discussed.

Fig. 2 elucidates the variation of collector thermal efficiency with respect to the mass flow rate for different concentrations of hybrid nanofluids. The studies were accompanied by a constant solar thermal intensity and an atmospheric temperature of $1000 \mathrm{~W} / \mathrm{m}^{2}$ and $25^{\circ} \mathrm{C}$. The inlet collector temperature was assumed to be $27^{\circ} \mathrm{C}$. The most influencing parameter which effects the solar thermal collector performance are mass flow rate, charactertics and concentration of nano particles. For all types of working fluids, the collector's thermal efficiency improves as the mass flow rate increases. The mass flow rate is exactly proportional to the Reynolds number as a result of this. This is significant because the heat capacity of the flowing fluid increases with Reynolds number and lower the mean wall temperature of the solar collector, lowering system thermal losses.

It can be observed that the system efficiency of FPSC with $\mathrm{Fe}_{2} \mathrm{O}_{4}$ /water nanofluid have significant performance improvement as it compared with water flows at a mass flow rate of 0.01 to $0.1 \mathrm{~kg} / \mathrm{s}$. However, the system with a hybrid nanofluid composed of zinc and ferrite appears to be superior to the ferrite nanofluid, indicating that the zinc addition with ferrite nano-particles synergistically enhances the system's performance. The collector efficiency has increased significantly with the increase of $\mathrm{Zn}-\mathrm{Fe}_{2} \mathrm{O}_{4}$ /water hybrid nanoparticles in water. It is obvious that the efficiency surged steeply up to a value of $0.03 \mathrm{~kg} / \mathrm{s}$ and then slowly till $0.1 \mathrm{~kg} / \mathrm{s}$. The increment in performance was insignificant beyond value of $0.06 \mathrm{~kg} / \mathrm{s}$. Furthermore, the highest collector 
efficiency for the FPSC system with a 0.5 percent concentration of $\mathrm{Zn}-\mathrm{Fe}_{2} \mathrm{O}_{4} /$ water hybrid nanofluids was increased by $6.6 \%$ when compared to $\mathrm{Fe}_{2} \mathrm{O}_{4} /$ water nanofluids. Because nanofluids have a greater thermal conductivity, reduces the overall thermal resistance throughout the FPSC, the reduces the local thermal barriers will decreases considerably at higher flow conditions.

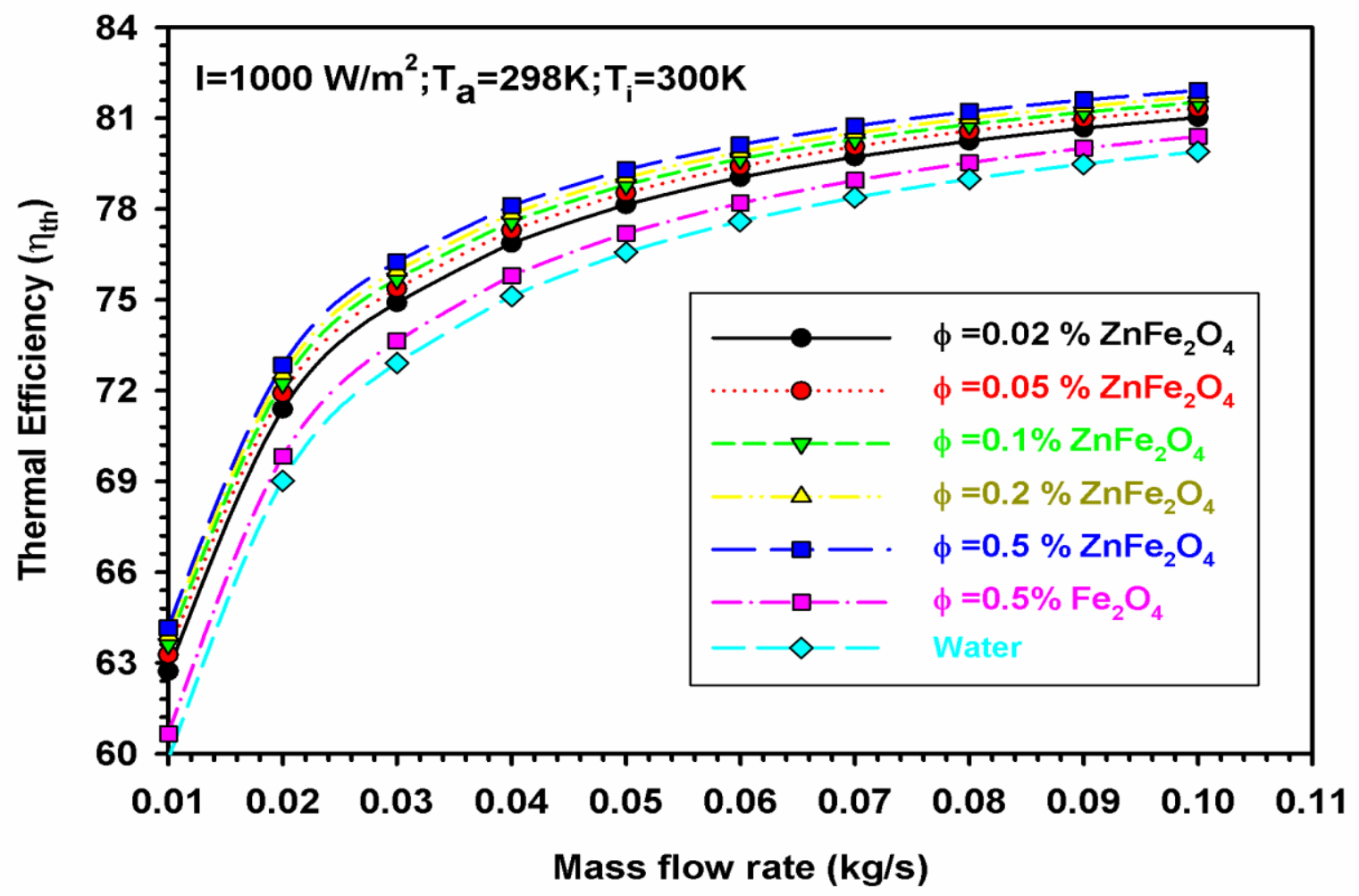

Fig. 2. Collector efficiency v/s mass rate.

The improvement in heat transfer coefficient of the system with the increment in rate of flow rate is depicted in Fig.3. The heat transfer coefficient was weak for the water based FPSC system. The FPSC system with $\mathrm{Fe}_{2} \mathrm{O}_{4}$ /water nanofluid shows that the better heat transfer coefficient was raised by $25.8 \%$ compared to conventional fluid. But, the system with hybrid nanofluid is significantly high related to the conventional fluid and $\mathrm{Fe}_{2} \mathrm{O}_{4} /$ water nanofluid systems for the corresponding mass flow rates. Improved heat transfer properties were evaluated by the viscosity of nanofluids and effective thermal conductivity. The heat transfer coefficient enhances with the raise in the concentration of hybrid nanofluids. The higher heat transfer coefficient can be characterized for the FPSC system with a $0.5 \%$ hybrid concentration at a flow rate of $0.1 \mathrm{~kg} / \mathrm{s}$. When compared to $\mathrm{Fe}_{2} \mathrm{O}_{4}$ /water nanofluid for the identical operating conditions, the convective 
heat transfer coefficient of $\mathrm{Zn}-\mathrm{Fe}_{2} \mathrm{O}_{4} /$ water hybrid nanofluid was increased by $10.3 \%$ to $42.05 \%$ for the $\phi$ values varying from 0.02 to 0.5 percent. This improvement is shown to be enhanced at higher temperatures, implying that more effective energy is generated at these temperatures due to a lower heat loss coefficient, resulting in increased efficiency. As a result, it's easy to see how the greater concentration and fluid flow rate would improve the system's heat transfer coefficient.

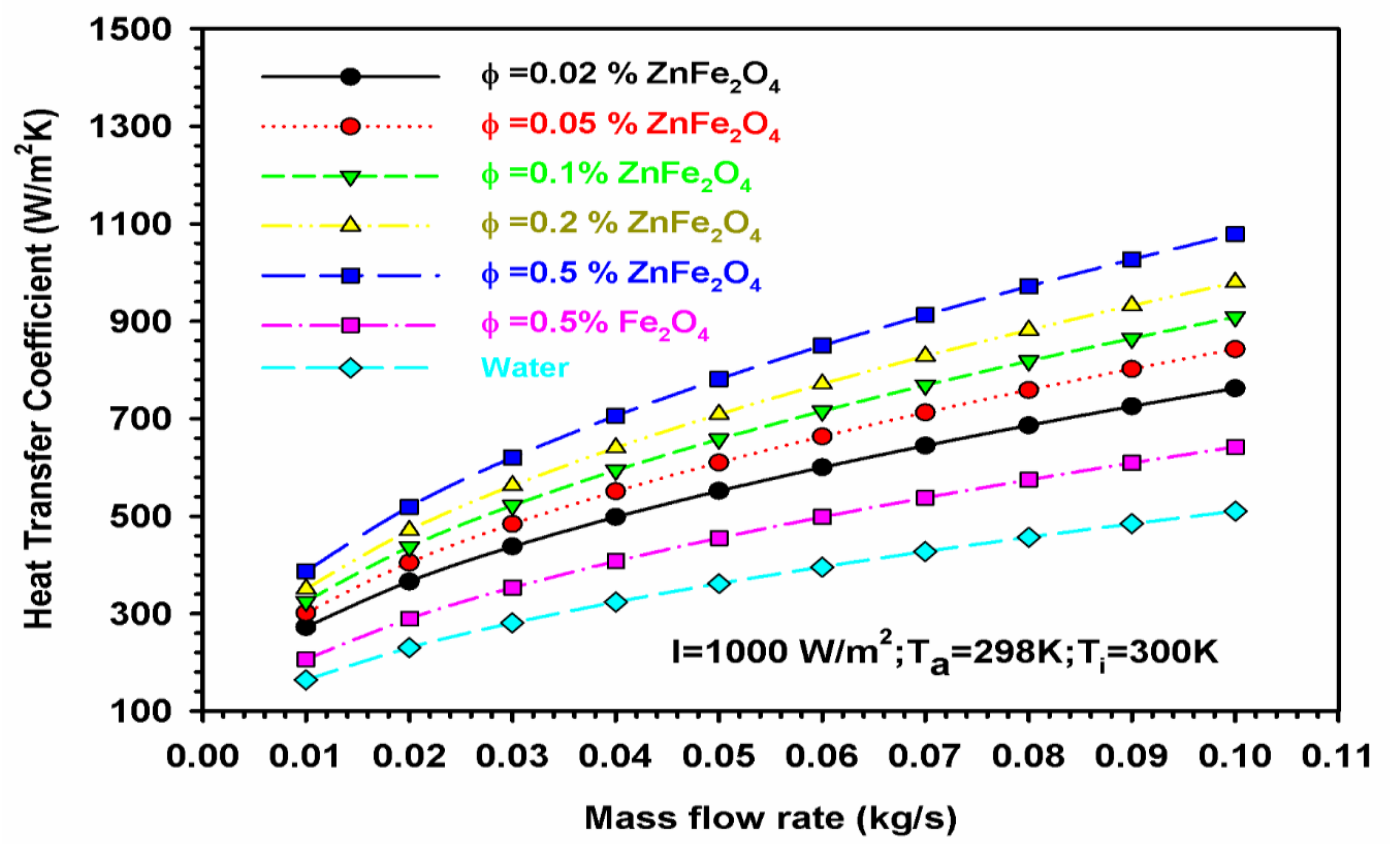

\section{Fig. 3. Deviation heat transfer coefficient as a result of mass flow rate and volume} concentration

The variations in first law and exergy efficiency pertaining to the Reduced Temperature Parameter (RTP) are plotted in Fig.4. The system with three types of fluids, namely, water, 0.5\% $\mathrm{Fe} 2 \mathrm{O} 4 /$ water nanofluid, and $0.5 \% \mathrm{Zn}-\mathrm{Fe}_{2} \mathrm{O}_{4} /$ water hybrid nanofluid, is taken for consideration for a constant solar heat flux of $1000 \mathrm{~W} / \mathrm{m}^{2}$ and a mass flow rate of $0.01 \mathrm{~kg} / \mathrm{s}$. The performance of the collector decreases with an increase in the reduced temperature parameter. This occurs because as RTPs increase, the temperature of the absorber plate rises, increasing heat losses to the atmosphere. Further, when the operating temperature of the FPSC increases, the density and viscosity of fluids seem to be reduced, which reduces the performance of the collector. Hybrid nanofluid with a $0.5 \%$ concentration is considered for this plot owing to its contribution to an 8.4\%improvement in collector efficiency as compared with water due to the enhancement in convective heat transfer coefficient. Energy efficiency, on the other hand, showed a steadily rising trend in relation to the 
increase in the reduced temperature parameter. This rise occurred due to that presence of more thermal energy to be converted into useful heat gain in the collector. While the black absorber plate attains thermal equilibrium with the sun, the exergetic performance of the system increases and reduces the energy destruction rate. The comparison study between the three working fluids results that, the hybrid nanofluid has the highest exergetic performance due to its superior thermal conductivity qualities. The maximum exergetic performance of $5.36 \%$ was obtained for the reduced temperature parameter of $0.03 \mathrm{Km}^{2} / \mathrm{W}$. Further, a rise in mass flow rate decreases the 356 performance due to a rise in pumping power.

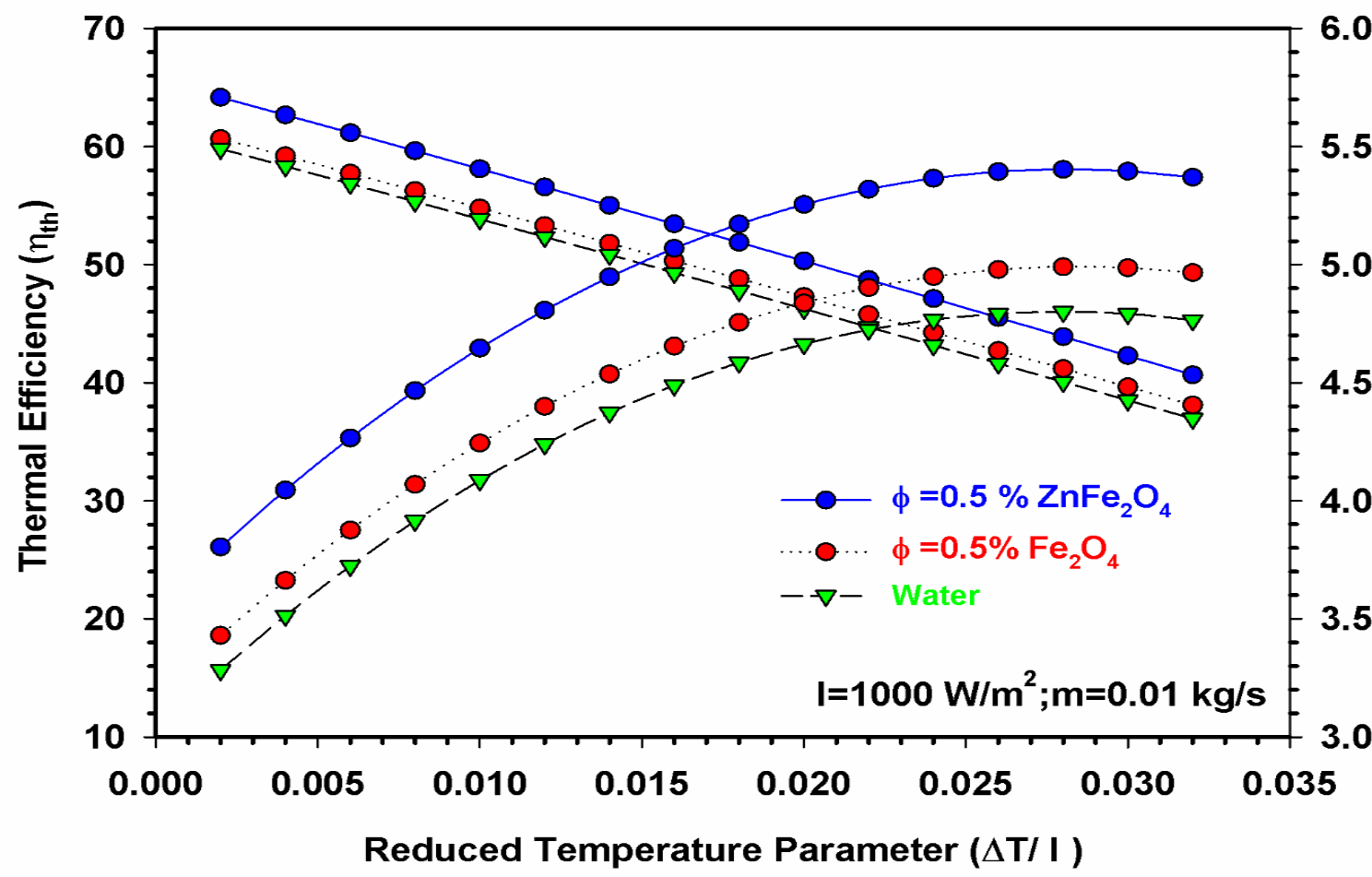

Fig. 4. Exergy and thermal performance of FPSCas a function of RTP

360

361

362

363 364

Figure 5 portrays the variation in exergy efficiency with regard to mass flow rate and volume concentration of $\mathrm{Zn}-\mathrm{Fe} 2 \mathrm{O} 4 /$ water hybrid nanofluids. A value of $3.73 \%$ exergy efficiency was recorded for a mass flow rate of $0.025 \mathrm{~kg} / \mathrm{s}$ and a volume concentration () of 0.5 . The maximum exergy performance was obtained with the minimum value of flow rate and maximum volume concentration. The exergy efficiency shows a declining trend with the mass flow rate and improving fashion with the volume concentration of hybrid nanofluids. This occurs because the exergy destruction rate improves with increase in fluid flow rate owing to the limited temperature 
differential between the FPSC components such as the sun, absorber plate, absorber tube, and working fluid. Increased pressure drop at greater flow rates, on the other hand, lowers average fluid temperature and increases exergy destruction owing to friction.

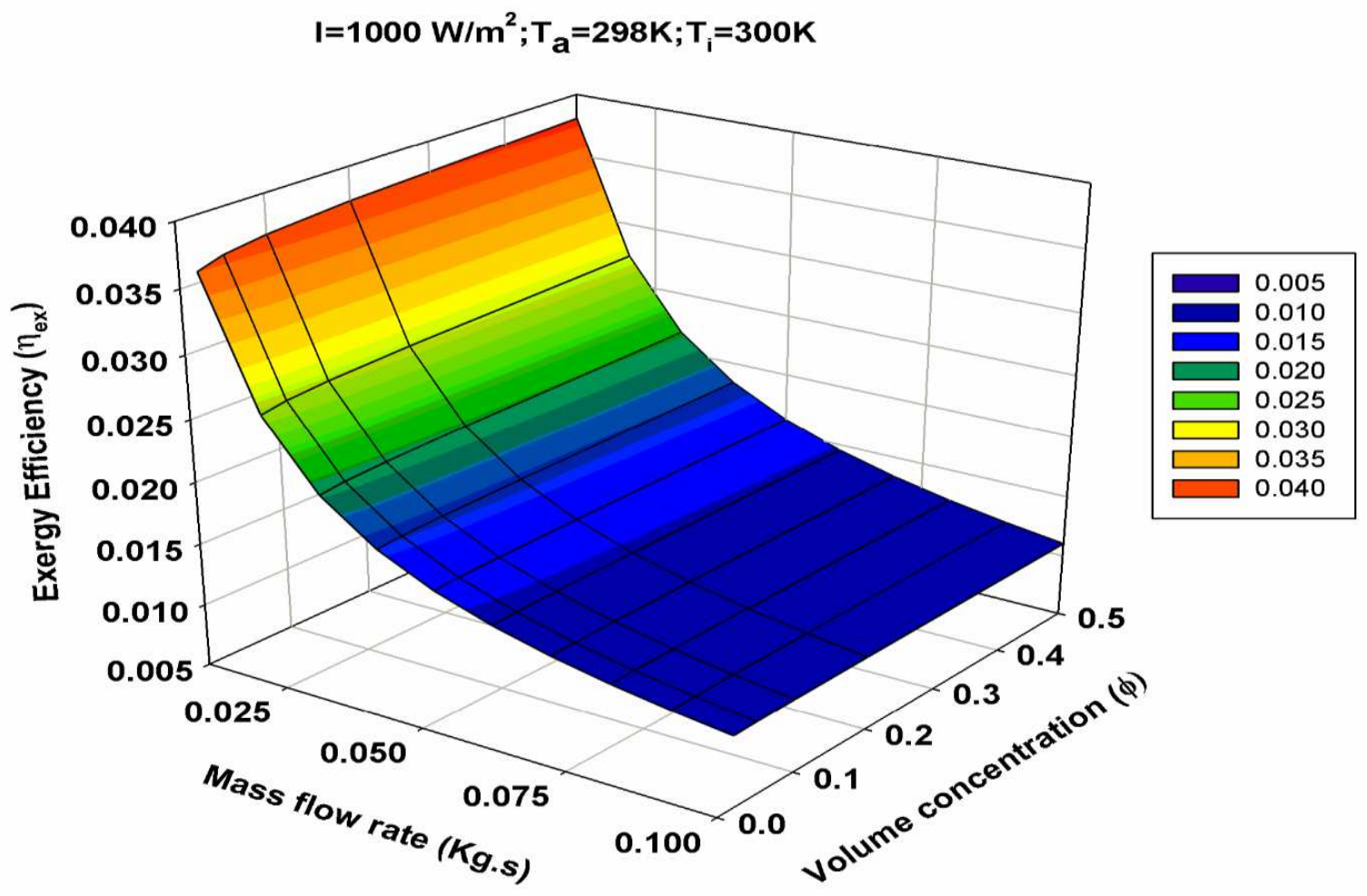

Fig. 5. Influence of fluid flow rates and particle volume concentrations on exergy efficiency

Figure 6 depicts the exergy losses and exergy destruction of FPSC system with respect to 372 fluid flow rate for the collector operates with various working fluids. The investigation was carried 373 out at a steady solar heat flux of $1 \times 10^{3} \mathrm{~W} / \mathrm{m}^{2}$ with the atmospheric temperature of $25^{\circ} \mathrm{C}$ and the 374 inlet collector temperature was assumed to be $27^{\circ} \mathrm{C}$. It is vividly understood that the destruction 375 of exergy monotonically raised with the increment in fluid flow rate inside the riser tubes. The 376 increment was initially significant and became less at the higher fluid flow rates. It indicates that 377 the generation of entropy was high at the augmented mass flow rates. On the other hand, the exergy 378 loss of the FPSC system drops with increased mass flow rates. Similar to the exergy destruction, 379 the loss in exergy was considerably reduced till the value of $0.04 \mathrm{~kg} / \mathrm{s}$ and less significant 380 afterwards. When the mass flow rates are raised, the heat transfer to the ambient are reduced 381 because the Reynolds number is increased, leads to rapidly removes energy from the walls of the solar collector's absorber. Compared to the nanofluids, the exergy destruction and exergy loss were 
expressively higher for the water. Further, $\mathrm{Zn}-\mathrm{Fe}_{2} \mathrm{O}_{4} /$ water hybrid nanofluid recorded lesser exergy destruction and exergy loss with the increment in mass flow rate compared to the nanofluid containing $\mathrm{Fe}_{2} \mathrm{O}_{4}$ nanoparticles. The fluid decreases exergy destruction and losses by a maximum of $3.7 \%$ when compared with water. On the whole, the hybrid nanofluid was assisted to reduce the irreversibility of the FPC system substantially, compared to other fluid fluids. As the Reynolds number raises considerably, the heat resistance within the collector decreases.

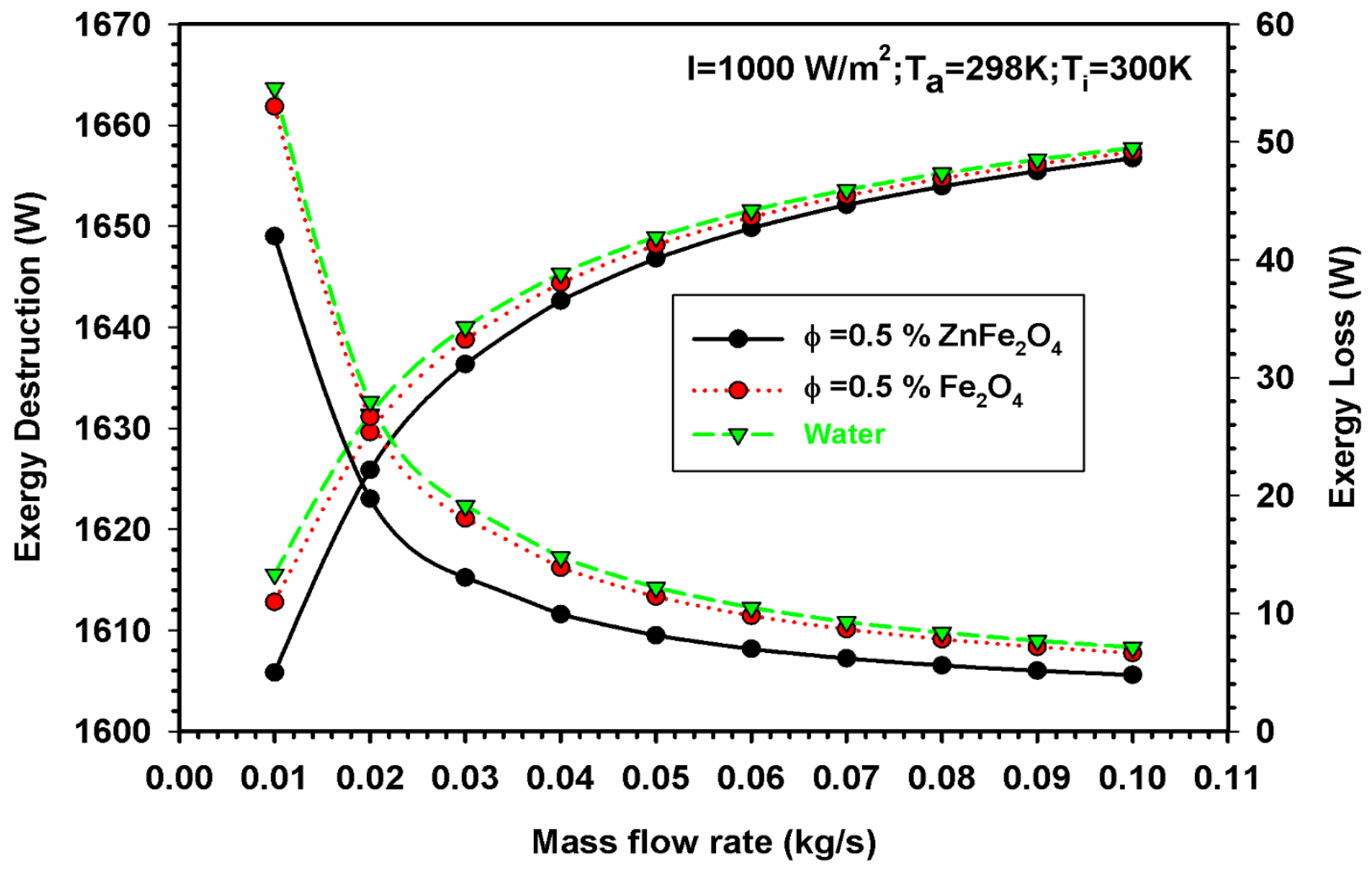

Fig. 6. Influence of mass flow rate on Exergydestructionandexergy losses

At a constant solar thermal intensity of $1 \times 10^{3} \mathrm{~W} / \mathrm{m}^{2}$ and a fluid flow rate of 0.01 $\mathrm{kg} / \mathrm{s}$, Fig.7. illustrates destruction in exergy values and losses in exergy values as a function of $\Delta \mathrm{T} / \mathrm{I}$. Among the exergy input values only around 3-5.5\% is converted to usable energy, since the rest is lost due to exergy losses and exergy destruction factors. As the sun's energy is collected by the collector, the system's total exergy is depleted. It's because of the large thermal gradient among the solar collector and the source; as the temperature variation decreases, the destruction inexergy is minimized to a lesser extent. It's also been found that utilizing hybrid $\mathrm{Zn}-\mathrm{Fe}_{2} \mathrm{O}_{4} /$ water nanofluids 
reduces the force of losses in exergy of the FPSC by maximum of 2.84 percent. $\mathrm{Fe}_{2} \mathrm{O}_{4}$ /water nanofluids have also been shown to effectively reduce the rate of irreversibilities with in process. The increased thermal conductivity properties of nanofluids are the reason for this. However, when it comes to exergy losses in the system, $\mathrm{Zn}-\mathrm{Fe}_{2} \mathrm{O}_{4} /$ water hybrid nanofluids are a superior alternative.

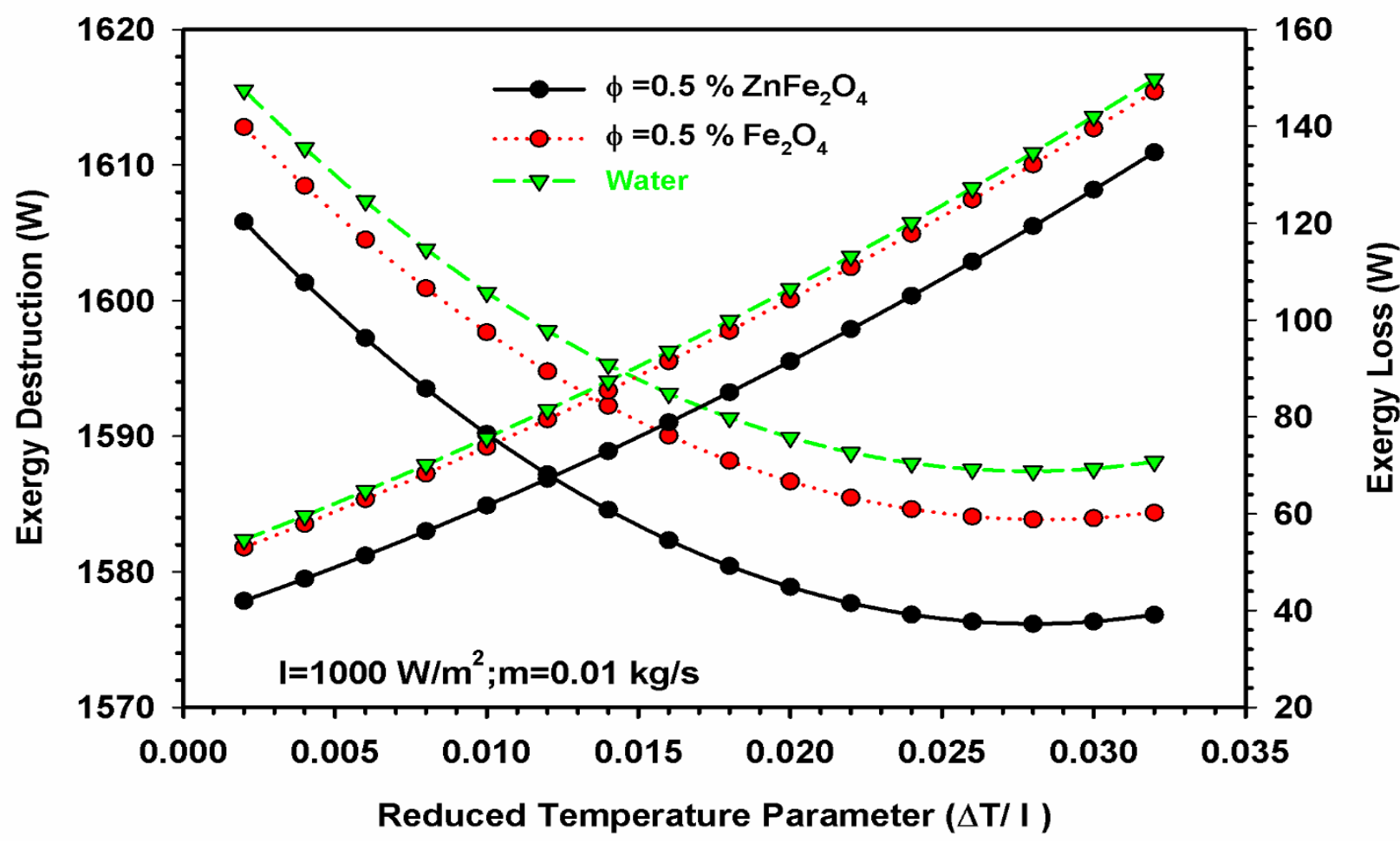

Fig. 7. Exergy losses and destruction as a function of $(\Delta T / I)$

Figure 8 depicts the changes in entropy generation and Bejan Number for the Reduced Temperature parameter. It is also fascinating to note that the accumulation of entropy gradually decreases in water for $0.5 \% \mathrm{Fe}_{2} \mathrm{O}_{4}$ nanofluid as well as for $0.5 \% \mathrm{Zn}-\mathrm{Fe}_{2} \mathrm{O}_{4} /$ water hybrid nanofluid as the working fluids have increased the reduction temperature parameter $\left(T_{i}-T_{a}\right) / I_{t}$. The inability of a system to convert available energy into useful tasks is shown by entropy generation. It is not typically advised to generate entropy at a faster rate. The entropy generation rate for the 0.5 percent $\mathrm{Zn}-\mathrm{Fe}_{2} \mathrm{O}_{4} /$ water hybrid nanofluid is $5.39 \mathrm{~W} / \mathrm{K}$, whereas it is $5.41 \mathrm{~W} / \mathrm{K}$ for 0.5 percent $\mathrm{Fe}_{2} \mathrm{O}_{4} /$ water nanofluids and $5.43 \mathrm{~W} / \mathrm{K}$ for water, respectively, among the selected working fluids. The physical significance of the Bejan number is shown in Eq (29). It is a non-dimensional number that represents the proportion of entropy generated by thermal energy transfer to the overall entropy 
generated by thermal energy transfer plus irreversibility induced internally by pressure drop and frictional losses happens at adiabatic conditions. A shift toward a greater Bejan number indicates that the system's dynamic responsiveness has improved. The Bejan number falls when the reduction temperature parameter is increased for a constant particle volume concentration. Because entropy generation due to $\Delta \mathrm{P}$ is less than that provided by irreversibility, the decrease in Bejan number is progressive rather than rapid.

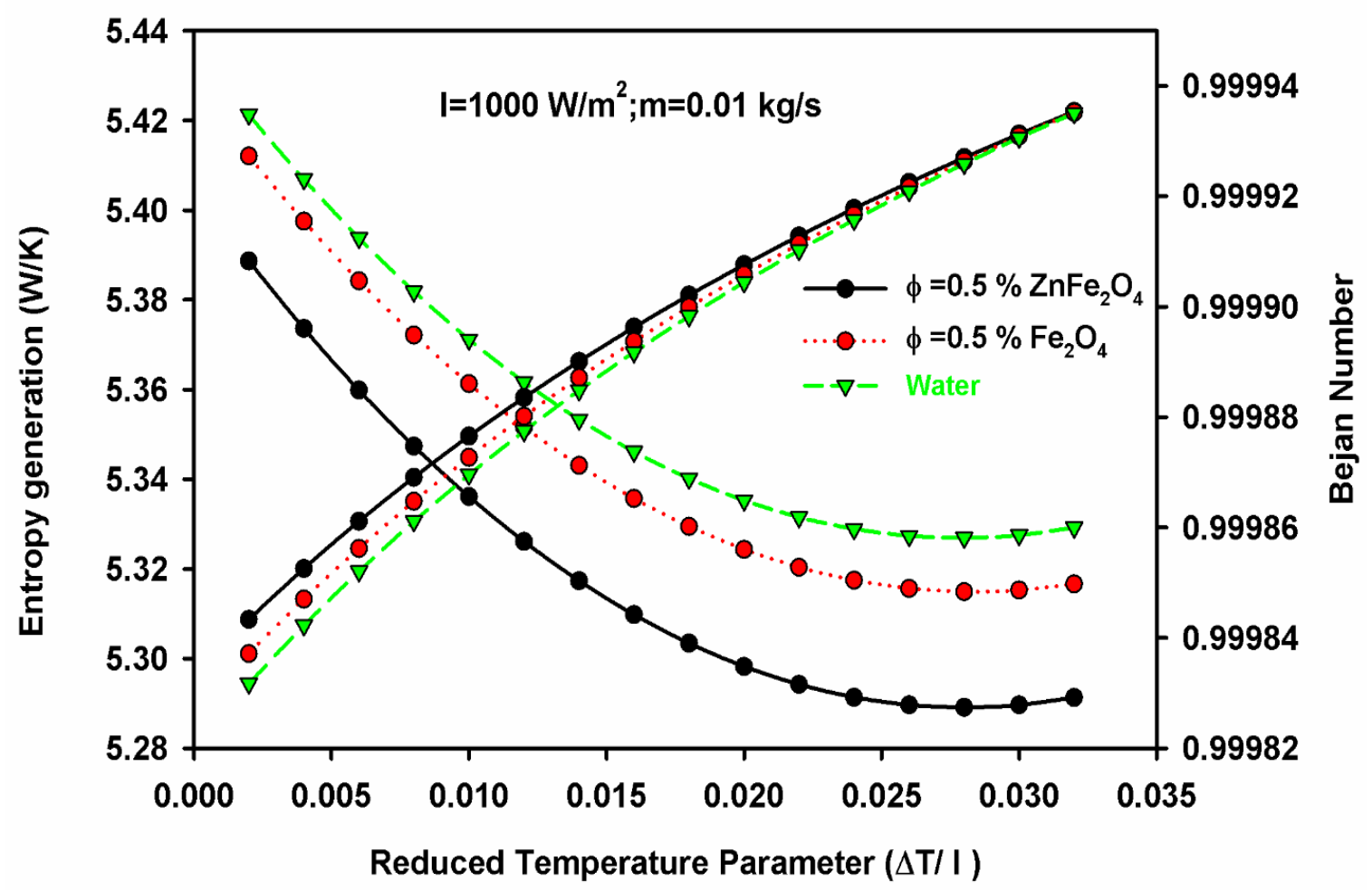

Fig. 8. Influence of $\Delta T / I$ on Bejan number and entropy generation of FPSC

\section{Conclusions}

An analytical study was performed to assess the effectiveness of a thermal flat plate solar collector using water, $\mathrm{Fe}_{2} \mathrm{O}_{4}$ /water nanofluid, and $\mathrm{Zn}-\mathrm{Fe}_{2} \mathrm{O}_{4}$ /water hybrid nanofluid as working fluids at various flow rates for varied volume concentrations. The developed regression polynomial form was use to calculate the thermal properties of all the working fluids. On the use of MATLAB codes, thermal model for the FPSC was solved and the first and second law-based performances were evaluated.

The following points highlight the key conclusions in the results. 
- At a nanoparticle concentration of $0.5 \%, \mathrm{Zn}-\mathrm{Fe} 2 \mathrm{O} 4 /$ water hybrid nanofluid provides a thermal enhancement of $6.6 \%$ in the collector when compared to $\mathrm{Fe}_{2} \mathrm{O}_{4} /$ water nanofluid. When compared to water, single nanofluids improve the collector's thermal performance by $7.83 \%$.

- While hybrid nanofluids give a superior thermal alternative than water and single nanofluids, they also showed a8.24\% increase in exergetic efficiency over $\mathrm{Fe}_{2} \mathrm{O}_{4} /$ water nanofluids.

- Whereas nanoparticles improve the performance of heat transfer fluids, there is an best possible volume concentration of nanoparticles beyond which its usage in a fluid is becomes less helpful to the energy and exergy transfer rate.

- The convective heat transfer flux in the flow area is significantly increased by nanofluids. $\mathrm{Fe}_{2} \mathrm{O}_{4} /$ water nanofluids and $\mathrm{Zn}-\mathrm{Fe}_{2} \mathrm{O}_{4} /$ water hybrid nanofluids both show a $25.8 \%$ and $52.6 \%$ increase in heat transfer coefficient, respectively.

- Exergy destruction due to energy transfer between the FPSC and the source attributed for $13.8 \%$ of total exergy destruction across the FPSC, whereas destruction in exergy due to friction recorded for the lower amount of exergy destruction at $0.05 \%$ of total exergy destruction.

- The greater enhancement in nanofluid thermal conductivity values, significantly reduces the of entropy generationrate in the system as the nanoparticles concentration in the fluid increases.

- The magnitude of entropy formulation in the FPSC increases when the mass flow rate is raised due to higher pumping losses happens in the system.

- The magnitude of mass flow rate are higher, the Bejan number is reduced due to the raise in pumping power losses.

\section{REFERENCES}

Abbasi S, Zebarjad SM, Baghban SHN, Youssefi A, EkramiKakhki MS (2016) Experimental investigation of the rheological behavior and viscosity of decorated multi-walled carbon nanotubes with $\mathrm{TiO}_{2}$ nanoparticles/water nanofluids. J Therm Anal Calorim 123(1):81-9.

Bellos E, Tzivanidis CJD (2018) Thermal analysis of parabolic trough collector operating with mono and hybrid nanofluids. J Sustain Energy Technol Assess 26:105-15. 
Bianco V, Chiacchio F, Manca O, Nardini S (2009) Numerical investigation ofnanofluids forced convection in circular tubes. Appl. Therm. Eng 29:3632-3642.

Bianco V, Manca O, Nardini S (2011) Numerical investigation on nanofluids turbulent convection heat transfer inside a circular tube, Int. J. Therm. Sci. 50: 341-349.

Bobbo S, Fedele L, Benetti A, Colla L, Fabrizio M, Pagura C, Barison S (2012) Viscosity of water based SWCNH and $\mathrm{TiO}_{2}$ nanofluids. Exp. Therm Fluid Sci. 36: 65-71.

Brinkman H. The viscosity of concentrated suspensions and solutions. J Chem Phys 1952:20(4):571.

Chakraborty S, Panigrahi PK (2020) Stability of nanofluid: A review, Appl. Therm. Eng. 115259.

Choi SU, J.A. Eastman JA (1995) Enhancing thermal conductivity of fluids with nanoparticles, Argonne National Lab, IL (United States).

Das SK, Putta N, Thiesen P, Roetzel W (2003) Temperature dependence of thermal conductivity enhancement for nanofluids. J. Heat Transfer 125: 567-574.

Duffie JA, Beckman WA (2013). Solar engineering of thermal processes solar engineering. John Wiley \& Sons Inc.

Esfe MH, Saedodin S (2015) Turbulent forced convection heat transfer and thermophysical properties of $\mathrm{MgO}$-water nanofluid with consideration of different nanoparticles diameter, an empirical study. J Therm Anal Calorim 119(2):1205-13.

Fedele L, Colla L, Bobbo S (2012) Viscosity andthermal conductivity measurements of waterbased nanofluids containing titanium oxide nanoparticles. Int. J. Refrig. 35: 1359-1366.

Gupta M, Singh V, Said Z (2020) Heat transfer analysis using zinc Ferrite/water (Hybrid) nanofluids in a circular tube: An experimental investigation and development of new correlations for thermophysical and heat transfer properties. Sustain. Energy Technol. Assess 39: 100720 .

Hamilton RL, Crosser O (1962) Thermal conductivity of heterogeneous two- component systems. Ind. Eng. Chem. Fundam 1 (3) :187-191. 
He Y, Men Y, Zhao Y, Lu H, Ding Y (2009) Numerical investigation into theconvective heat transfer of $\mathrm{TiO} 2$ nanofluids flowing through a straight tube under the laminar flow conditions. Appl. Therm. Eng 29 :1965-1972.

Khin N, Choudhury IA, Masjuki HH, Aoyama H (2017) Theoretical analysis to determine the efficiency of a $\mathrm{CuO}$-water nanofluid based-flat plate solar collector for domestic solar water heating system in Myanmar. Sol. Energy 155: 608-619.

Labib MN, Nine MJ, Afrianto H, Chung H, Jeong H (2013) Numerical investigationon effect of base fluids and hybrid nanofluid in forced convective heat transfer, Int. J. Thermal Sci 71:163-171.

Lotfi R, Saboohi Y, Rashidi AM (2010) Numerical study of forced convective heat transfer of nanofluids: comparison of different approaches, Int. Comm. Heat Mass Trans 37:74-78.

Mahian O, Kianifar A, Sahin AZ, Wongwises S (2014) Entropy generation during $\mathrm{Al}_{2} \mathrm{O}_{3} /$ water nanofluid flow in a solar collector: effects of tube roughness, nanoparticlesize, and different thermophysical models. Int J Heat Mass Transf 78:64-75.

Mahian O, Kianifar A, Sahin AZ, Wongwises S (2014) Performance analysis of a minichannelbased solar collector using different nanofluids. Energy Convers Manag 88:129-38.

Maiga SE, Palm SJ, Nguyen CT, Roy G, Galanis N (2005) Heat transfer enhancement by using nanofluids in forced convection flows. Int J Heat Fluid Flow. 1:26(4):530-46.

Maxwell JC. A treatise on electricity and magnetism.Oxford:Clarendon Press; 1873.

Minea AA (2017) Challenges in hybrid nanofluids behavior in turbulent flow: recent research and numerical comparison. J Renew Sustain Energy Rev 71:426-34.

Murshed SMS, Leong KC, Yang C (2005) Enhanced thermal conductivity of $\mathrm{TiO}_{2}$ - water based nanofluids. Int. J. Therm. Sci. 44 (4): 367-373.

Mwesigye A, Huan Z (2015) Thermal and thermodynamic performance of a parabolic trough receiver with Syltherm800- $\mathrm{Al}_{2} \mathrm{O}_{3}$ nanofluidas the heat transfer fluid. J Energy Procedia 75:394-402. 
Okonkwo EC, Abid M, Ratlamwala TAH (2019) Comparative study of heat transfer 515 enhancement in parabolic trough collector based on modified absorber geometry. EnergyEng ASCE 145(3):1-16.

Okonkwo EC, Abid M, Ratlamwala TAH, Abbasoglu S, Dagbasi M (2019) Optimal analysis of entropy generation and heat transfer in parabolic trough collector using green synthesized $\mathrm{TiO}_{2}$ /water nanofluids. J Sol Energy Eng 141(3):310111.

Okonkwo EC, Ratlamwala TAH, Abid M (2019) Energy, exergy, exergoeconomic, and exergoenvironmental study of a parabolic trough collector using a converging-diverging receiver tube. International Journal of Exergy 29(2-4):131-154..

Otanicar T, Phelan PE, Prasher RS, Rosengarten G, Taylor RA (2010) Nanofluid based direct absorption solar collector, J. Renew. Sust.Energy 2:033102.

Ozil E, Yaşar K (1987) Analysis of flat plate collectors. In: Yuncu, H., Paykoc,E., Yener, Y. (Eds.) Solar Energy Utilization. Springer Dordrecht 188-213. parabolic trough solar receiver. Appl Therm Eng 67(1-2):579-86.

Pak BC., Cho YI (1998) Hydrodynamic and heat transfer study of dispersed fluids with

Petela R (1964) Exergy of heat radiation. J Heat Transfer 86(2):187.

Prakasam MJS, ThottipalayamVellingiri A, Nataraj S (2017) An experimental study of the mass flow rates effect on flat-plate solar water heater performance using $\mathrm{Al}_{2} \mathrm{O}_{3} /$ water nanofluid.Therm Sci 21:S379-88.

Rasih RA, Sidik NAC, Samion S (2019) Recent progress on concentrating direct absorption solar collector using nanofluids. JTherm Anal Calorim 137:903-22.

Said Z, Saidur R, Rahim NA (2014) Optical properties of metal oxides based nanofluids. Int. Commun. Heat Mass Transfer 59: 46-54. 
561

562

563

564

565

566

567

Sajid MH, Said Z, Saidur R, Adikan FRM, Sabri MFM, Rahim NA (2014) A time variant investigation on optical properties of water based $\mathrm{Al}_{2} \mathrm{O}_{3}$ nanofluid. Int. Commun. Heat Mass Transfer 50: 108-116.

Sarkar J, Ghosh P, Adil A (2015) A review on hybrid nanofluids: recent research, development and applications. Renew. Sustain. Energy Rev. 43: 164-177.

Sundar LS, Sharma K, Singh MK, Sousa A (2017) Hybrid nanofluids preparation, thermal properties, heat transfer and friction factor-a review. Renew Sustain Energy Rev 68:185-98. Suresh S, Venkitaraj KP, Selvakumar P, Chandrasekar M (2011) Synthesis of $\mathrm{Al}_{2} \mathrm{O}_{3}-\mathrm{Cu}$ /water hybrid nanofluids using two step method and its thermo physical properties. Colloids Surf A 388 (1-3): 41-48.

Takabi B, Salehi S (2014) Augmentation of the heat transfer performance of a sinusoidal corrugated enclosure by employing hybrid nanofluid. JAdvMech Eng 6:147059.

Tyagi H, Phelan P, Prasher R (2009) Predicted efficiency of a low-temperature nanofluid 581 based direct absorption solar collector, J. Sol. Energy. Eng 13:041004-1. Vajjha RS, Das DK, Mahagaonkar BM (2009) Density measurement of different nanofluids and their comparison with theory. Pet. Sci. Technol. 27 (6): 612-624. 


\section{Acknowledgements}

569 Authors would like to express their deep gratitude to Audisankara College Engineering

570 \&Technology, Gudur to provide research facilities for carry out this research work

571 Availability of data and materials

572 Data will be made available upon request

573 Authors' contributions

574 P. Michael Joseph Stalin: Conceptualization, Methodology, Writing - original draft.

575 T.V. Arjunan: Validation. and Supervision.

576 Mohammed Almeshaal: Formal analysis, Investigation,

577 Murugesan Palaniappan: Writing - review \& editing.

578 B.Prabu:Visualization.

579 P. Manoj Kumar: Validation,

580 Declarations

581 Ethics approval and consent to participate Not applicable

582 Consent to publish

583 Not applicable

584 Competing interests

585 The authors declare no competing interests

586 Funding

587 Not applicable 